\title{
Transatlantica
}

Revue d'études américaines. American Studies Journal

\section{Alfred E. Eckes, Jr. \& Thomas W. Zeiler. Globalization and the American Century.}

Cambridge : Cambridge University Press, 2003, 344p.

\section{Jacques Portes}

\section{(2) OpenEdition}

\section{Journals}

Édition électronique

URL : http://journals.openedition.org/transatlantica/876

DOI : $10.4000 /$ transatlantica.876

ISSN : 1765-2766

Éditeur

AFEA

Référence électronique

Jacques Portes, « Alfred E. Eckes, Jr. \& Thomas W. Zeiler. Globalization and the American Century. », Transatlantica [En ligne], 1 | 2005, mis en ligne le 24 avril 2006, consulté le 29 avril 2021. URL : http:// journals.openedition.org/transatlantica/876 ; DOI : https://doi.org/10.4000/transatlantica.876

Ce document a été généré automatiquement le 29 avril 2021.

\section{c) (요 $\ominus$}

Transatlantica - Revue d'études américaines est mis à disposition selon les termes de la licence Creative Commons Attribution - Pas d'Utilisation Commerciale - Pas de Modification 4.0 International. 


\section{Alfred E. Eckes, Jr. \& Thomas W. Zeiler. Globalization and the American Century.}

Cambridge : Cambridge University Press, 2003, 344p.

Jacques Portes

1 Depuis quelques années, la mondialisation est l'objet de bien des études et suscite nombre de controverses. Ces deux professeurs d'histoire (Eckes de l'université d'Ohio et Zeiler de celle du Colorado) se sont irrités de cette vision très contemporaine et, dans le présent ouvrage, ils démontrent selon un plan chronologique que le transfert de fonds et la volonté américaine d'ouvrir des marchés soutiennent la politique de leur pays depuis la fin du XIXe siècle. Mais on ne peut parler de mondialisation que depuis 1983 : "globalization is a complex, controversial, and synergistic process in which improvements in technology...combine with the deregulation of markets and open borders to bring about vastly expanded flows of people, money, goods, services, and information ». (1) Ce faisant les deux auteurs sont conscients des transformations suscitées par les deux guerres mondiales et la guerre froide, car le gouvernement des États-Unis a pris des initiatives qui ont eu de nombreux effets sur les échanges de personnes et de biens. Ils ne se placent pas dans la lignée directe des historiens « révisionnistes » de l'université du Wisconsin qui avaient, dans les années 1960, tenté d'expliquer la politique de leur pays par la seule " porte ouverte ", car ils attribuent aux grandes firmes multinationales une réelle autonomie dans la recherche de marchés mondiaux. De plus, ils insistent également sur l'accélération des bouleversements dans le domaine de l'information et de la culture grâce à Internet.

2 Les dix chapitres, chacun d'une vingtaine de pages, suivent un découpage chronologique classique : l'impérialisme (1898-1913), la mondialisation de la Première Guerre mondiale, le rêve américain des années 20, la rupture de la crise de 29, la redéfinition due à la Seconde Guerre mondiale, la guerre froide, les bouleversements des années 60 , les crises des années 70 , le règne du libre-échange et la mondialisation du nouveau millénaire. 
3 La brièveté des chapitres indique bien qu'il ne s'agit pas d'une narration événementielle, mais d'une approche du type relations internationales pimenté par des données sur le commerce international et les échanges culturels. Les deux auteurs sont très au courant des derniers développements historiographiques qu'ils utilisent avec finesse. À chaque reprise, ils font le point sur les avancées de la mondialisation en donnant des exemples de développement des échanges et de réussites remarquables de firmes américaines : la politique impérialiste du président McKinley est réévaluée alors que le Wild West show et le premier cinéma sont des preuves d'une précoce mondialisation; les années 20 relancent le mouvement accentué par le triomphe transatlantique de Lindbergh, l'essor du tourisme et le rôle du téléphone; bien entendu, la crise interrompt ce mouvement auquel des personnalités comme Cordell Hull et Tom Watson d'IBM restent attachés et, quelques années plus tard, McDonald et Nike sont devenus les fleurons de la mondialisation.

4 À chaque période, des exemples qui prouvent que la recherche des marchés, la volonté de puissance internationale ont toujours sous-tendu la politique américaine, même quand des grandes fractions de l'opinion ou du monde politique s'y opposent. La fin de la guerre froide, qu'ils attribuent largement et de façon discutable à la réussite économique des années Reagan, relance durablement la mondialisation fondée sur un certain consensus post-keynésien et sur l'extraordinaire développement des industries et des pratiques de la communication moderne. Alors que le succès des grands conglomérats semblait annoncer un monde supra-national, les attentats du 11 septembre 2001 ont redonné toute leur place aux États-Nations.

Cet ouvrage bien informé, dont les annexes sur le commerce et les échanges internationaux peuvent être utiles, ne remporte pas vraiment l'adhésion. Il ne s'agit pas plus d'un manuel que d'un essai convaincant. Le découpage scolaire en périodes courtes conduit à des répétitions et nuit à l'explication profonde des phénomènes : pourquoi certaines firmes ou activités culturelles s'imposent plus que d'autres à travers le monde, pourquoi l'idéologie libérale a-t-elle connu un tel renouveau glorieux dans les années 1980, les mouvements américains d'opposition à la mondialisation sont-il d'arrière-garde ou ont ils de l'avenir?

INDEX

Thèmes : Recensions

\section{AUTEUR}

JACQUES PORTES

Université Paris 8 